\title{
The first records of climatic changes in the basin of Lake Khikushka (Eastern Sayan) in the Late Glacial - Holocene
}

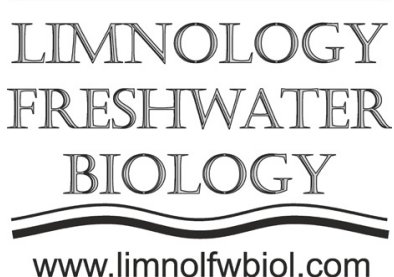

\author{
Amosova A.A. ${ }^{1}$, Chubarov V.M. ${ }^{1}$, Smelyy R.V. ${ }^{1}$, Kulagina N.V. ${ }^{2}$ \\ ${ }^{1}$ Vinogradov Institute of Geochemistry, Siberian Branch of the Russian Academy of Sciences, Favorsky St., 1A, Irkutsk, 664033, Russia \\ ${ }^{2}$ Institute of the Earth's Crust, Siberian Branch of the Russian Academy of Sciences, Lermontov Str., 128, Irkutsk, 664033, Russia
}

\begin{abstract}
A complex of X-ray methods was used to reconstruct the geochemical evolution in the catchment basin of high-mountain Lake Khikushka (Eastern Siberia, Russia) with the undisturbed environment: wavelength-dispersive X-ray fluorescence method was used to determine the elemental composition, and X-ray powder diffraction method was used to determine the mineral composition of the $123 \mathrm{~cm}$ long Khik-15 sediment core taken from a depth of $30 \mathrm{~m}$. The proposed for wavelengthdispersive X-ray fluorescence analysis the fusion sample preparation technique requires a sample weighing only $110 \mathrm{mg}$, which allows analyzing each centimeter of the core and eventually achieve a uniquely high resolution of paleoclimatic reconstructions of global and regional climatic and environmental changes. Four periods of natural variability of climate, the environmental conditions, and dynamics of the relative intensity of chemical weathering over the past 14500 years in the Lake Khikushka basin were identified using cluster analysis results obtained by the Tilia program.
\end{abstract}

Keywords: Wavelength dispersive X-ray fluorescence analysis, X-ray powder diffraction, mineral composition, lake bottom sediments, paleoclimate

\section{Introduction}

Complex studies of bottom sediments from highmountainous sites outlying from large cities unaffected by the sources of permanent anthropogenic impact, where undisturbed ecosystems prevail, make it possible to understand the key indicators of climate variability and the natural environment, to estimate the rates of climatic changes, to obtain qualitative data for testing the capabilities of climate models and to reproduce changes in the paleoclimate. Mountain water bodies, as a rule, are pure geosystems and they are usually rarely subjected to direct anthropogenic impact. At the same time, they are affected by severe weather conditions, the weathering rates of rocks in their watersheds are relatively low, and the soil cover is thin. Therefore, the geosystems of such lakes respond quickly and energetically to any changes both in the lake and in its catchment basin. Sedimentation in mountain boreal lakes is very sensitive to such changes, recording them in vertical variations in the composition of sediments and their structure. As a result, undisturbed lake deposits can be used as key natural archives of information for reconstructing the natural environment of the past for a long time with high resolution.

\section{Material and methods}

As the object of study, the tarn, flowing, and high-altitude lake Khikushka (1956 m above sea level), located in the mountains of the East Sayan was selected. Its surface area is $0.3 \mathrm{k}^{\mathrm{m}} 2$, the depth reaches $42 \mathrm{~m}$. The $123 \mathrm{~cm}$ long Khik-15 core was taken from a depth of $30 \mathrm{~m}$, the age of the deposits at the core bottom was determined by AMS radiocarbon analysis and is 14500 years.

To reconstruct the geochemical evolution of the catchment, the X-ray fluorescence analysis method was used, which was implemented on a wavelengthdispersive X-Ray Fluorescence spectrometer S8 Tiger (Bruker AXS, Germany). The proposed technique (Amosova, 2019) allows the determination of the main rock-forming ( $\mathrm{Na}, \mathrm{Mg}, \mathrm{Al}, \mathrm{Si}, \mathrm{P}, \mathrm{K}, \mathrm{Ca}, \mathrm{Ti}, \mathrm{Mn}, \mathrm{Fe}$ ) elements from small mass samples, which is important when there is a shortage of the studied core material of bottom sediments. The values of loss on ignition at 950 ${ }^{\circ} \mathrm{C}$ including "combined water," carbon dioxide from carbonates, and organic matter were determined by the gravimetric technique and varied from 7 to $16 \mathrm{wt}$. \%.To supplement and detail the geochemical reconstruction, the mineral (phase) composition of the terrigenous component of sediments was first determined by X-ray

*Corresponding author.

E-mail address: amosova@igc.irk.ru (A.A. Amosova). 
powder diffraction method (Smelyy, 2019) on the X-ray Diffractometer D8 Advance (Bruker AXS, Germany). $\mathrm{X}$-ray fluorescence analysis was carried out for each centimeter of Khik-15 core, and X-ray phase analysis was performed for every third centimeter of the core.

\section{Results and discussion}

According to X-ray diffraction results, the qualitative mineral composition of the terrigenous component is represented by the following minerals and mineral species: quartz, albite, microcline, feldspars, layered minerals (muscovite, clinochlore, vermiculite), amphibole. No carbonate minerals are detected. Based on obtained by wavelength-dispersive X-ray fluorescence rock-forming oxides contents the main geochemical indices (chemical index of alteration CIA, chemical index of weathering CIW, plagioclase index of alteration PIA, the chemical proxy of alteration CPA, index of compositional variation ICV) were calculated to assess the degree of deformation and weathering of the rocks of the catchment in various climatic and landscape conditions. The distributions of main rockforming oxides contents and geochemical indices over the depth of the core sediment section are obtained. Cluster analysis (using the Tilia program based on square-root-transformation of the percentage data and stratigraphically constrained cluster analysis by the method of incremental sum of squares) was used to identify four periods of natural variability of climate and environment in the basin of Lake Khikushka, and to reconstructe dynamics of the relative intensity of chemical weathering over the past 14500 years. The results of the study of the weathering and landscape of the basin of the Lake Khikushka basin based on a comprehensive analysis of bottom sediments using modern research methods allowed us to obtain the data necessary to study the geochemical evolution of lake geosystems of the Baikal region in contrasting climatic conditions at the end of the last glaciation and for the entire period of the modern interglacial.

\section{Acknowledgments}

The research was performed using equipment of the Siberian Branch of the Russian Academy of Sciences Joint use centers (Geodynamics and Geochronology Center and Isotope-geochemical Research Center) with the financial support of the Russian Foundation for Basic Research (project № 19-05-00328).

\section{References}

Amosova A.A., Chubarov V.M., Pashkova G.V. et al. 2019. Wavelength dispersive X-ray fluorescence determination of major oxides in bottom and peat sediments for paleoclimatic studies. Applied Radiation and Isotopes 144: 118-123. DOI:10.1016/j.apradiso.2018.11.004

Smelyy R.V., Kaneva E.V., Oshchepkova A.V. et al. 2019. Determination of the mineral composition of the lake bottom sediments by x-ray diffraction method and physico-chemical modelling. Journal of Siberian Federal University. Chemistry 3: 382-394. DOI: 10.17516/1998-2836-0135 